\title{
UMA SUPERVISÃO CLÍNICO-INSTITUCIONAL NA REFORMA PSIQUIÁTRICA NA PERSPECTIVA DA ANÁLISE INSTITUCIONAL
}

\author{
CLINICAL-INSTITUTIONAL SUPERVISION IN THE PSYCHIATRIC REFORM \\ UNDER THE PERSPECTIVE OF INSTITUTIONAL ANALYSIS
}

\begin{abstract}
Ana Kalliny Severo1 iD (0000-0002-9548-6394), Solange L'A bbate ${ }^{2}$ iD ${ }_{(0000-0003-2163-0901)}$
${ }^{1}$ Universidade Federal do Rio Grande do Norte, Faculdade de Ciências da Saúde do Trairi, Curso de Psicologia, Santa Cruz, Rio Grande do Norte, Brasil. <kallinysevero@yahoo.com.br>

${ }^{2}$ Universidade Estadual de Campinas, Faculdade de Ciências Médicas, Programa de Pós-Graduação em Saúde Coletiva, Campinas, São Paulo, Brasil.
\end{abstract}

Resumo A supervisão fomenta mudanças nos serviços na perspectiva da atenção psicossocial. Sua institucionalização ocorreu nos campos da clínica, formação e gestão em saúde e expressa forças contraditórias instituídas e instituintes. A investigação que deu origem a este artigo analisou o processo de supervisão clínico-institucional em duas equipes da rede de saúde de um município do interior do Nordeste. O referencial teórico-metodológico utilizado foi o da análise institucional, na perspectiva da socioclínica. O processo ocorreu em 12 encontros, de março de 2011 a fevereiro de 2012, e foi registrado em diários institucionais. Neste processo, evidenciamos que: a análise da encomenda e, principalmente, a das demandas mobilizaram o processo de supervisão; existiram conflitos entre o uso de casos clínicos e a construção dos projetos terapêuticos singulares, como também na compreensão sobre o processo formativo da supervisão; houve cooperações e rivalidades entre as equipes na construção do cuidado em redes municipais; surgiram desafios no cuidado à crise no contexto das redes regionais na perspectiva da atenção psicossocial. O dispositivo supervisão precisa ser expandido e interiorizado, constantemente revisto, para que esteja em consonância com os pressupostos da atenção psicossocial, assim como para propiciar momentos de experimentação dos trabalhadores como grupos-sujeitos.

Palavras-chave atenção psicossocial; análise institucional; rede de atenção psicossocial; supervisão em saúde mental.
Abstract Supervision promotes changes in the services under the perspective of psychosocial care. Its institutionalization took place in the fields of clinical practice, training and management in health, and it expresses contradictory forces that were established and that also establish these forces. The present study originated from a research that analyzed the clinicalinstitutional supervision process within two teams of the health care network of a municipality in the countryside of the Northeastern region of Brazil. The theoretical-methodological framework used was that of the institutional analysis, under a socioclinical perspective. The process took place throughout 12 meetings from March 2011 through February 2012, and was recorded on institutional journals. During this process we evidenced that: the analysis of the order, and especially of the demands, mobilized the supervision process; there were conflicts regarding the use of clinical cases and the development of unique therapeutic projects, as well as regarding the understanding of the supervision training process; there were rivalries and cooperation between the two teams regarding the development of care in municipal networks; challenges arose regarding the care of the crisis in the context of the regional networks under the perspective of psychosocial care. The supervision directive must be expanded and internalized, and constantly reviewed so it can be in line with the presuppositions of psychosocial care, and also to provide moments of experimentation on the part of the workers as groups-subjects.

Keywords psychosocial care; institutional analysis; psychosocial care network; supervision in mental health. 


\section{Introdução}

A supervisão é um dispositivo fundamental no campo da reforma psiquiátrica brasileira, pois tem possibilitado às equipes um espaço de formação, qualificação e discussão acerca do processo de cuidado desenvolvido na atenção psicossocial. Nesse sentido, a pesquisa que deu origem a este artigo objetivou analisar um processo de supervisão clínico-institucional vivenciado em uma equipe de um Centro de Atenção Psicossocial (CAPS). Para tanto, descreveu-se o processo de institucionalização da supervisão, na perspectiva teórico-metodológica da análise institucional, e analisou-se uma experiência de supervisão vivenciada por uma das autoras deste artigo.

Para analisar a institucionalização da supervisão no processo da reforma psiquiátrica brasileira, é importante percorrer alguns campos de coerência que, embora distintos, entrecruzam-se. Debater tal tema remonta às discussões que se referem ao entrecruzamento da clínica, formação e gestão em saúde (Ferigato e Dias, 2013). Nesse sentido, é importante interrogar-se quais são as contradições que aparecem na institucionalização desse dispositivo nos diversos campos de coerência e de intervenção, em relação ao modo de atenção psicossocial almejado no contexto brasileiro.

A supervisão encontra no eixo da clínica um dos campos mais consolidados histórica e teoricamente, que surge na construção do caso clínico, sua principal ferramenta (Ferigato e Dias, 2013). Nesse âmbito, a institucionalização da clínica psicanalítica ocorreu diante da necessidade de as instituições formadoras analisarem e supervisionarem os candidatos a psicanalistas em seu processo de atendimento (Coutinho, Medeiros e Trindade, 2012; Campos, 2012). A International Psychoanalytical Association (IPA), fundada por Freud e Ferenczi em 1910, foi um importante espaço de desenvolvimento da supervisão na clínica. A supervisão, nesse contexto, tinha por finalidade "normatizar a análise e afastar da formação 'analistas selvagens', transgressivos ou julgados carismáticos demais para praticar convenientemente a psicanálise" (Roudinesco, 2000, p. 151; destaques no original).

Em relação à formação, Saraiva e Nunes (2007) assinalam que a supervisão constitui uma das mais antigas formas de ensinar e aprender um ofício, uma técnica ou uma profissão. No início dos anos 1920, foi incorporada ao ensino da psicanálise, tornando-se atualmente um dos três pilares básicos da formação de um analista, juntamente com o aprendizado teórico e o processo analítico ou psicoterapêutico.

Outras áreas de ensino, como a medicina, a psiquiatria e a psicologia, adotaram tal modelo, que pode ser definido como "um processo de habilitação do candidato", e a "atitude do supervisor deve estimular, no supervisionando, o desenvolvimento de suas próprias habilidades" (Zaslavsky, Nunes e Eizirik, 2003, p. 298). 
Diversas críticas foram feitas à supervisão, dentre elas a impossibilidade de discuti-la com a liberdade que permita pensá-la criticamente, bem como o melhor modo de inseri-la no processo formativo (Fuks, 2002); o não detalhamento dos passos que cada dupla, supervisor/supervisionando, deve seguir para atingir os objetivos previstos na aprendizagem; a inexistência de sistematização sobre a sua condução em relação aos objetivos e critérios de avaliação, apontando assim sua função de controle da supervisão (Saraiva e Nunes, 2007).

Neste sentido, a supervisão envolve relações de poder, já que o supervisor está autorizado pela instituição a garantir e monitorar a qualidade dos serviços oferecidos pelos terapeutas de seu corpo clínico. Talvez seja justamente a questão das relações de poder que impeça uma discussão mais livre do aspecto controle da supervisão, ficando a maior parte dos artigos estudados centrada na questão da supervisão como função didática apenas (Saraiva e Nunes, 2007, p. 266-267).

No campo da gestão, também há atravessamentos das relações de podersaber instituídas. O modelo taylorista/fordista, a administração clássica e o modelo burocrático exercem grande influência na constituição histórica da organização do trabalho e do gerenciamento no setor saúde (Carvalho e Chaves, 2011). A maioria das escolas de administração foi criada objetivando disciplinar o trabalhador, retirando dele sua iniciativa crítica, delegando aos programas e às normas a tarefa de operar o trabalho cotidiano e ao trabalhador a sua execução, de modo a docilizá-lo, torná-lo útil e produtivo (Campos e Amaral, 2007). Algumas escolas apostaram mais na tarefa de disciplinar e controlar os comportamentos dos trabalhadores; outras centraram-se na subjetividade do trabalhador, ganhando-lhe a alma.

Na perspectiva taylorista, o trabalhador é visto como aquele que não sabe o que é necessário para o exercício do seu trabalho, pois é a administração científica que deve reger as normas necessárias para isso (Campos, 2007). Desse modo, existe aí uma diferença na distribuição do saber-poder, em que o trabalhador seria disciplinado e controlado para o exercício do seu trabalho pelos administradores ou supervisores, passando assim por um processo de infantilização.

As principais características incorporadas ao setor saúde expressam-se por meio da separação entre concepção e execução (fragmentação do trabalho) (Carvalho e Chaves, 2011). Assim, o exercício da supervisão no campo da saúde vem tendo por finalidade fiscalizar o trabalhador na execução de uma determinada atividade.

Em relação à prática psiquiátrica, a supervisão esteve historicamente entrelaçada a uma rede de dispositivos que buscavam (re)produzir relações 
de poder disciplinadoras sobre os indivíduos e sobre a população (Foucault, 2006; Castel, 1987).

No interior dos asilos, o sistema de poder era

[...] assegurado por uma multiplicidade, por uma dispersão, por um sistema de diferenças e de hierarquias, e mais precisamente, pelo que poderíamos chamar de uma disposição tática na qual os diferentes indivíduos ocupam um lugar determinado e cumprem um certo número de funções precisas (Foucault, 2006, p. 9).

Nesse funcionamento tático do poder encontram-se distribuídos médicos, vigilantes e pacientes, e o psiquiatra exerce, nos hospitais psiquiátricos, as funções de administração, clínica e formação. O espaço asilar é gerenciado pelo psiquiatra, cuja presença deve "fazer o espaço funcionar como um corpo que cura por sua própria presença, seus próprios gestos, sua própria vontade" (Foucault, 2006, p. 235).

A função clínica envolve as relações médico-paciente e estudantes. O rito de apresentação clínica será "o grande exemplificador do poder psiquiátrico" (Foucault, 2006, p. 234). Nele, o psiquiatra reúne em torno do doente o maior número de espectadores, interroga e faz comentários sobre suas respostas, de maneira a demonstrar que conhece sua doença e sua história de vida. Esse momento é identificado como de formação para os alunos espectadores, em que o psiquiatra é aquele que atua em um duplo registro: "será ao mesmo tempo aquele que cuida e aquele que detém a palavra do mestre, será médico e mestre ao mesmo tempo" (Foucault, 2006, p. 232).

Assim, vemos uma prática psiquiátrica que foi desenvolvida até o início do século $\mathrm{XX}$, reunindo características muito similares àquelas instituídas na administração de pessoas, na clínica e na formação em torno da supervisão. Dessa maneira, se as funções de clínica, formação e gestão têm uma historicidade própria, que delimita o processo de institucionalização da supervisão, resta-nos interrogar sobre as transformações sofridas pelas perspectivas anteriormente adotadas para seus usos na reforma psiquiátrica brasileira.

Severo (2014) desenvolveu uma análise sócio-histórica acerca da supervisão no contexto da reforma psiquiátrica, revelando que, nas experiências reformistas desenvolvidas nos anos 1980 e 1990, é possível perceber um movimento instituinte muito potente revelado na criação e na reinvenção de diversos dispositivos, inclusive da própria supervisão. A supervisão propiciou o fortalecimento do movimento instituinte nos arranjos dos serviços substitutivos, seja nos CAPSs, nas equipes de saúde mental atuantes na atenção básica e nos cursos de formação, seja nos modos de gestão e clínica. No entanto, algumas experiências mostraram a permanência de uma separação entre a supervisão clínica e a institucional. 
Nos anos 2000, a política ministerial de investimento financeiro nas supervisões clínico-institucionais foi insuficiente diante das demandas sociais relacionadas às mudanças necessárias nos serviços para a consolidação da atenção psicossocial. A supervisão mostrou-se uma aposta potente para o fortalecimento da rede de cuidados, mas foram necessárias diversas outras iniciativas que a acompanhassem, que englobavam desde a discussão em torno de sua concepção até reformulações na política de recursos humanos e formação para a atuação na rede de atenção psicossocial (Severo, 2014).

A despeito de sua importância, ainda há escassez de investigações empíricas sobre processos de supervisão clínico-institucional, não sendo possível afirmar que seu uso nos CAPS possa garantir discussões teórico-práticas que vão além do indivíduo e da doença (Coutinho, Medeiros e Trindade, 2012). Além disso, Onocko Campos e colaboradores (2009, p. 21) apontam para a escassez de supervisões clínico-institucionais, existindo ainda "o risco de transformar-se em espaço de 'saber-poder' que opera sobre as equipes, com total descolamento da gestão local".

No entanto, os desafios apresentados nas mudanças nos serviços substitutivos indicam a necessidade de estímulo a dispositivos coletivos que fomentem processos crítico-reflexivos e autoanalíticos (Luzio, 2013). Por conseguinte, a problematização da supervisão torna-se fundamental para que a contradição, a tensão entre o instituinte e o instituído, possa aparecer. Este artigo apresenta alguns resultados da tese da primeira autora, constituída por uma pesquisa-intervenção que teve como objetivo analisar um processo de supervisão clínico-institucional vivenciado juntamente com a equipe de um CAPS, numa cidade do interior de um estado do Nordeste.

\section{Escolha teórico-metodológica: a socioclínica institucional e os caminhos da pesquisa}

Para a realização dessa pesquisa-intervenção, o referencial teórico-metodológico escolhido foi o da análise institucional (AI), na sua vertente da socioclínica. A AI foi criada nas décadas de 1950/1960 na França, com base em experiências das crises dos movimentos da juventude, da escola, do hospital e das igrejas, dentre outras, bem como "da crise interna das instituições na sociedade capitalista monopolista, naquelas décadas" (Coimbra, 1995, p. 54; Lourau, 2014).

A tarefa da AI é desvelar o não dito das instituições, mediante a problematização e o questionamento às instituições que permaneciam ocultas (Lourau, 2004). Outro objetivo importante seria desvelar a relação dialética instituinte-instituído-institucionalização em todos os âmbitos sociais. Para isso, ela "pode intervir EM estabelecimentos e COM dispositivos, mas sempre 
visando apreender a 'instituição' em seu sentido ativo" (Rodrigues e Souza, 1987, p. 27; destaques das autoras).

Desse modo, as instituições formam uma rede social e acabam por unificar e atravessar os indivíduos, que por meio de sua práxis mantêm ou criam novas (Lourau, 2004; Monceau, 2008; 2012). Elas não são uma natureza, mas mantêm 'em pé' a máquina social, conformando as formas sociais de modo universal (instituído) e também produzindo-a (instituinte) (Rodrigues e Souza, 1987).

Monceau (2012) afirma que recentemente vem se constituindo na França uma modalidade de formação inicial e contínua que possibilita a análise das práticas profissionais principalmente nas profissões da educação, da saúde e do trabalho social. Isso tem se mostrado importante tanto na educação, resultando na possibilidade reflexiva de que o trabalho educativo é um trabalho político (Freinet), como também na saúde, permitindo desvelar os mecanismos transferenciais e contratransferenciais na relação médico-paciente (Balint) (Monceau, 2008).

O processo de intervenção analisado na pesquisa que deu origem a este artigo ocorreu de março de 2011 a fevereiro de 2012, por meio de encontros mensais que contaram com a participação das equipes CAPS e NASF e, ocasionalmente, do secretário municipal de saúde. O diário foi usado como forma de registrar/analisar o que aconteceu nos encontros. Trata-se de uma prática antiga, reportando-se às práticas do diário de pesquisa e do diário íntimo (Hess, 2006; Pezzato e L'Abbate, 2011).

A escrita do diário é transversal, permitindo explorar os diversos objetos (pensamentos, sentimentos, leitura de textos, entre outros). Por meio do diário, temos uma acumulação do registro, das experiências, reflexões e sentimentos, e com o transcorrer do tempo ele pode adquirir uma dimensão histórica, tornando-se um banco de dados (Hess, 2006).

$\mathrm{Na}$ experiência aqui analisada, o diário assumiu um papel relevante no processo de pesquisa, pois serviu ao mesmo tempo como registro dos movimentos institucionais vivenciados e como um processo reflexivo sobre o 'ser supervisora' da rede de saúde mental de um município. Além disso, foi proposto que o grupo participante desenvolvesse seu diário, o que não chegou a ser efetivado. A equipe demonstrava dificuldade em escrever sobre sua prática, não aderindo a esse tipo de procedimento dentro ou fora do contexto da supervisão.

O município onde se realizou o processo de supervisão possui uma área geográfica de 513 metros quadrados (Instituto Brasileiro de Geografia e Estatística, 2010) e uma população de 20.354 habitantes, sendo 17.084 na área urbana e 3.270 na área rural, com 9.961 homens e 10.393 mulheres. Está situado em uma região de saúde cuja cidade principal é distante 282 mil qui- 
lômetros da capital e que abrange 25 municípios, com uma população total de mais de 295 mil habitantes.

A rede de saúde do município é composta por vinte estabelecimentos. Na zona urbana há um hospital municipal, uma maternidade, uma policlínica, nove postos de saúde e seis pontos de apoio prestando serviços à atenção básica, além de um CAPS tipo I. Existia ainda no município uma equipe do Núcleo de Apoio à Saúde da Família (NASF).

O CAPS I, onde se realizou a supervisão, foi criado em 21 de julho de 2006 e funciona de segunda a sexta-feira, das 7h às 17h. É um serviço de referência no atendimento em saúde mental para a população de outros quatro municípios, somando uma população de aproximadamente 35.415 habitantes. Sua equipe era composta no período da supervisão, já indicado, por 17 profissionais: uma psiquiatra, uma psicóloga, uma enfermeira, uma nutricionista, duas assistentes sociais, um farmacêutico, uma auxiliar de enfermagem, duas auxiliares de farmácia, uma artesã, um técnico administrativo e coordenador do serviço e a equipe de apoio (uma chefe de cozinha, uma auxiliar de cozinha, duas pessoas que trabalhavam na limpeza, uma recepcionista). A carga horária de trabalho dos profissionais de nível superior variava bastante, e a maioria trabalhava dois ou três dias por semana. A equipe do NASF era composta por dois fisioterapeutas, um psicólogo, um nutricionista e um educador físico.

Dentre as atividades desenvolvidas pelo serviço, constavam: oficinas terapêuticas, grupos terapêuticos, consultas psicológicas, orientações do serviço social, visitas domiciliares e passeios. O serviço atendia 77 usuários nas modalidades intensivo e semi-intensivo, caracterizado pela equipe como intensivos os que frequentavam os dois turnos e faziam quatro refeições diárias no CAPS; e semi-intensivos os que ficavam apenas um turno do dia.

\section{Encomenda e demanda}

A encomenda para realizar a intervenção surgiu em novembro de 2010, de um convite da representação do Ministério da Saúde do Nordeste para a pesquisadora participar de uma seleção para projetos de financiamento de supervisão em saúde mental. Contudo, foi enfatizado que a supervisão seria para a rede de saúde mental e não apenas restrita ao CAPS. O convite originou-se da publicação do Edital Supervisão VI-Ad, de 2010 (Brasil, 2010), no qual consta que o objetivo da supervisão seria possibilitar um espaço de discussão e de estudo das equipes técnicas dos diversos serviços que compõem a Rede de Atenção Psicossocial (RAPS), a respeito dos casos clínicos, dos projetos terapêuticos, da dinâmica dos serviços, das articulações com o território onde o CAPS de referência está situado, dos processos de trabalho, da gestão e da clínica na perspectiva intersetorial. Para identificar melhor a encomenda, realizamos, ainda no período da seleção, uma reunião com a 
coordenadora do CAPS indicado para conversar acerca das dificuldades e das necessidades do serviço.

Sobre a encomenda em socioanálise, Lourau (1993) afirma que ela tem origens em demandas individuais e dos grupos. Ele analisa que:

“[o]s responsáveis, as pessoas que têm autoridade para requerer uma intervenção que, enfim, passam a encomenda, também têm demandas individuais. Portanto, existe uma grande diversidade e muitas contradições entre todas as demandas possíveis da população envolvida" (Lourau, 1993, p. 31).

O pedido para realizar a intervenção ocorre na medida em que os organizadores traduzem essas demandas em uma encomenda que lhes permita entrar em contato com um profissional ou equipe interventor(a). As demandas, base para a encomenda, são as "solicitações, carecimentos e desejos dos participantes do grupo com o qual se vai trabalhar. Mas que, inicialmente afinadas com a encomenda, podem sofrer mudanças no decorrer do processo de intervenção" (L'Abbate, 2012, p. 200). Desse modo, o processo de supervisão norteou-se pela análise constante das demandas apresentadas pelo grupo, considerando que estas podem ser diversas e que a encomenda pode expressar uma "traição a essas demandas" (Lourau, 1993, p. 31), uma vez que expressam parcialmente seu conjunto heterogêneo.

\section{O estudo de casos clínicos e a construção dos projetos terapêuticos singulares}

Durante o processo de intervenção, diversas vezes alguns profissionais da equipe solicitavam explicitamente a discussão de casos, mas ao longo dos encontros traziam muitas outras demandas. No início da intervenção, as instituições que atravessavam as práticas profissionais, até então invisíveis, foram se insinuando cada vez mais fortemente, provocando um movimento analítico. 'O estudo do caso clínico' foi um analisador importante que revelou, a nosso ver, diversos conflitos, colocando em questão o funcionamento da equipe, a formação dos profissionais, o CAPS e a própria supervisão.

Afirmamos a necessidade de, na perspectiva da atenção psicossocial, superar a construção do caso de forma instituída no campo de saúde, no qual há um profissional que sabe mais do que a equipe e do que o usuário e conduz a delimitação e os procedimentos para resolução do caso. No Projeto Terapêutico Singular (PTS), esses diferentes movimentos precisam ser construídos simultaneamente pelos diversos sujeitos envolvidos, inclusive por usuários e familiares (Severo, 2014). “Para uma co-produção de problematização será necessário que a equipe reconheça a capacidade/poder das pessoas interferirem na sua própria relação com a vida e com a doença" (Oliveira, 2008, p. 282). 
O atendimento aos usuários de álcool e outras drogas apareceu diversas vezes como um sério problema para a equipe. Num dos casos relatados em relação a esse problema, chamou-nos atenção a situação de um usuário com idade em torno de 40 anos, que residia com a mãe idosa, ela própria apresentando um sofrimento psíquico grave. A mãe recusava a presença do CAPS e afirmava que o serviço fazia mal a seu filho. Ele, por sua vez, cuidava da casa, da mãe e de si mesmo, com muito zelo, de acordo com a própria equipe. Em uma das discussões, a equipe afirmou que ele tinha problemas com a polícia. A equipe dizia que o diagnóstico dele era F-20, esquizofrenia, com comorbidade. No prontuário estava registrado uma internação no hospital psiquiátrico antes de ele ir ao CAPS. Em relação ao pai, o usuário afirmava que não tinha muito a dizer, mas que seu pai, quando vivo, também bebia e 'colocava moral'. Esta expressão, no interior do Nordeste, é utilizada quando um homem quer expressar sua autoridade perante os demais. No prontuário, ainda estava escrito que ele apresentava delírio persecutório.

Segundo os relatos da equipe, quando esse usuário fazia ingestão de álcool, ficava 'xingando' todos à sua volta, inclusive as pessoas da comunidade. Antes, dizia apenas que os outros o provocavam e que a 'bebida para ele não era problema, era solução'; agora dizia que ele também provocava as pessoas. Após algumas intervenções desenvolvidas nas oficinas terapêuticas, uma das assistentes sociais contou que quando questionado da última vez sobre o uso do álcool, ele afirmara que não sabia responder se a bebida era problema ou solução.

Na maioria das supervisões, a equipe se mostrava sempre muito preocupada com o fato de o usuário apresentar um comportamento agressivo na rua, além de a população e a própria polícia cobrarem da equipe um controle dos atos dele e de outros usuários de álcool ou outras drogas. Por diversas vezes, questionamos qual o papel do CAPS em um caso como esse, se era de controle ou de cuidado.

Em uma das calorosas discussões acerca do atendimento ao usuário, percebemos que existia uma divisão na equipe a esse respeito. Enquanto alguns defendiam a adoção de medidas punitivas, o grupo de técnicos mais recente no serviço, no qual estava uma artesã que vinha conseguindo um vínculo com o usuário, posicionava-se a favor da continuidade do tratamento.

Retomei a história desse usuário no serviço, de como ele não aderia anteriormente a nenhuma atividade no CAPS e como visualizava um avanço no caso na medida em que estaria conseguindo aderir melhor às atividades, falar mais sobre sua situação. Parte da equipe reconheceu os avanços e reafirmou a perspectiva do acolhimento, outros afirmaram que 'ele só quer uma desculpa para beber' (diário institucional; grifo nosso). 
Em meio à discussão, o coordenador do serviço destacou que em conversa anterior com o usuário afirmara que iria levar o caso à supervisão e que, depois disso, daria uma resposta para ele sobre sua situação.

A expectativa é que a supervisora desse uma resposta para os problemas enfrentados, reafirmando o que queriam ouvir. Porém, expliquei que não forneceria uma resposta, que estávamos a discutir o caso, para assim construir algumas alternativas (diário institucional).

Nesse sentido, a expectativa da equipe era de que a supervisão pudesse responder à questão: como executar esse controle do usuário. A partir desse dia, passamos a refletir com a equipe no sentido de que o CAPS vive de modo permanente esse lugar instituído socialmente de ter de administrar as pessoas que demonstram risco social, mas deve procurar cuidar delas e tratá-las em liberdade. E quem está na ponta assume esse lugar difícil, acaba sentindo o peso de ter de fazer escolhas.

Nas discussões que a supervisora fez com o grupo, houve dificuldades de analisar essa questão, pois, de maneira geral, percebíamos problemas relacionados à continuidade dos atos assistenciais pactuados nas discussões acerca dos PTSs, por exemplo. Quando tentávamos colocar em análise, algumas justificativas apareciam, principalmente relacionadas ao tudo-fazer de todos, "aqui todos fazem tudo" (diário institucional), e desse modo não seria necessário realizar a pactuação da organização dos atos assistenciais por meio, por exemplo, do técnico de referência. Assim, a construção de uma linha de cuidado no serviço era difícil de ser feita.

Na supervisão clínico-institucional, Luzio (2010, p. 113) ressalta que diversas vezes os

[...] profissionais, embora destaquem formalmente a importância da supervisão institucional, deixam transparecer as demandas pessoais de supervisão de casos, de acordo com seus enquadres teóricos, sem levar em conta o contexto institucional, isto é, o serviço, a rede, a gestão, a política pública (Luzio, 2010, p. 113).

Durante a supervisão, ao mesmo tempo que tentávamos problematizar o lugar de controle em que a sociedade queria colocar o CAPS, havia uma demanda por uma verdade absoluta sobre a situação do usuário, de como fazê-lo parar com as brigas que causava na rua. Em relação aos usuários com uso problemático de drogas, Tedesco e Souza (2009) analisam os modos de conceber a clínica, apontando que quando se parte da perspectiva de que o principal investimento deve ser a abstinência, o foco do tratamento é a droga como provocadora de todos os males, e a participação ativa do usuário no processo é completamente excluída. Nesse contexto, o tratamento passa a ter 
como única estratégia possível a "criação e intensificação de força psíquica e, ou, moral de rechaço ao 'mau hábito', força de oposição ao forte e danoso elo entre usuário e droga" (Tedesco e Souza, 2009, p. 146).

Em virtude das campanhas proibicionistas antidrogas vigentes, há uma forte demanda socialmente construída para que os CAPS se posicionem em uma lógica de controle dos usuários e funcionem na lógica da abstinência. Isso chegou à supervisão sob a demanda também por uma supervisão de controle, autoritária, que desconsiderasse a participação e o desejo do próprio usuário (Severo, 2014). O CAPS, ao funcionar de acordo com o modo psicossocial, deve ter como postura ética selecionar essas demandas sociais, não lhes responder da mesma maneira, promovendo a escuta e a participação do usuário no processo de cuidado, assim como o respeito às diferenças no meio comunitário.

\section{A supervisão como espaço de formação ou capacitação?}

Nesse período, diante das demandas para discussão em torno das situações relacionadas ao uso de álcool e outras drogas, sugerimos textos que poderiam ser pesquisados virtualmente ou até mesmo disponibilizados diretamente, mas os profissionais, em geral, não liam os textos indicados, justificando não ter tempo para a leitura. Isso dificultava muito o processo de discussão e problematização coletiva. Dessa maneira, por numerosas vezes, diversas interrogações surgiam para nós sobre como fortalecer a formação no dispositivo supervisão. As discussões teóricas sobre clínica e redução de danos, quando ocorreram, restringiram-se à apresentação por parte da supervisora, o que gerava muitos incômodos e angústias de nossa parte. Diante desse incômodo, resistíamos em dar continuidade a uma formação 'capacitação'.

Destacamos a necessidade de que a equipe pudesse ter no seu cotidiano espaços de discussão, de formação, de estudos para possibilitar uma ampliação na capacidade de análise sobre os problemas vivenciados. Uma das dificuldades para isso é que, hegemonicamente,

[...] na maioria dos municípios, ainda persiste a velha lógica de treinamento para situações específicas de saúde, em que participam alguns trabalhadores. Estes, na condição de representantes do serviço ou do município, teriam no máximo a atribuição de, ao retornar para a unidade, repassar o treinamento recebido para os demais profissionais (Luzio, 2010, p. 114).

Onocko Campos (2012) considera que o modo de formação na supervisão deve ser sempre transmitir uma forma de conhecer e não um saber pronto, sendo o modo de conhecer e o próprio conhecimento algo processual, e a formação "se dá também pela experiência" (Campos, 2012, p. 170). A autora 
aponta que essa forma de conhecer torna-se um problema por não ser o modo hegemônico; assim, o trabalho do supervisor deve ser "valorizar esse saber que advém da experiência do encontro com o paciente" (Campos, 2012, p. 170). Desse modo, delineia-se uma "clínica intersubjetiva, que não se dá na relação dual, privada, mas que é efeito de um encontro complexo que envolve pacientes, profissionais, instituição e território" (Campos, 2012, p. 170).

Ao explorar a multiplicidade e a heterogeneidade de vozes e relações, conseguimos visualizar outros saberes que foram compondo o movimento instituinte nas situações vivenciadas. No entanto, havia uma expectativa em torno do saber acerca dos casos clínicos e da patologia, assim como de uma resposta absoluta vinda do supervisor para resolução dos problemas que deveria ser dada por parte deste.

\section{A construção do cuidado em redes (inter)municipais: dilemas entre rivalidades e cooperação}

No que diz respeito à supervisão em rede, diversas dificuldades surgiram, pois com a mudança da coordenação do serviço CAPS, seu antigo coordenador assumiu um cargo no NASF. Dessa maneira, relações de competição acabaram acontecendo entre o CAPS e o NASF. Existia demanda de supervisão por parte das duas equipes, mas as rivalidades tomavam o lugar do compartilhamento de responsabilidades necessárias nas supervisões de rede.

Ao final do primeiro dia com as duas equipes (março de 2011), ainda no primeiro semestre da supervisão, percebemos que havia um receio da equipe do CAPS de ficar sem a supervisão. Programamos para o mês seguinte um dia de supervisão dividido em dois turnos, em um deles um encontro com a equipe do CAPS e no outro um encontro com a equipe do NASF. Fiz isso por perceber que era necessária uma aproximação maior, naquele momento, junto ao NASF, uma redefinição de sua função na rede. E ainda porque mediante a presença da equipe do NASF, a equipe do CAPS silenciava, incomodava-se, inquietava-se e não participava da reunião. Assim, pensei em inicialmente garantir um espaço de escuta para os dois grupos para alinhar suas funções na rede de saúde e promover o fortalecimento das equipes. Em reuniões posteriores, realizamos encontros conjuntos entre o CAPS e o NASF para que as duas equipes pudessem se integrar e construir relações de cooperação (diário institucional).

As relações de disputa estavam acontecendo desde a mudança da Secretaria de Saúde e de coordenação do serviço. O coordenador do NASF na época da supervisão foi coordenador do CAPS, e saiu porque discordava da forma de administração de recursos financeiros pela Secretaria de Saúde. Sabíamos que existiam críticas e acusações entre os serviços a respeito do seu funciona- 
mento e da relação com a gestão municipal. Com essas acusações, as equipes mantinham uma relação marcada pela desconfiança entre si, que terminava por atrapalhar a construção das pactuações conjuntas no cuidado.

As disputas foram parcialmente superadas em alguns momentos, e alguns casos puderam ser compartilhados, com estratégias de trabalho sendo traçadas. No caso do usuário já relatado com problemas relacionados ao álcool, a articulação do CAPS com o NASF foi essencial para produzir um cuidado à família, e foram compartilhadas estratégias de cuidado da mãe do usuário. A mãe acreditava que o CAPS fazia mal a ele, por isso, após uma discussão conjunta do caso, os profissionais conseguiram uma pessoa da família que auxiliou no cuidado medicamentoso à mãe.

Acerca do papel do NASF, percebemos que existiam confusões quanto à sua relação com a atenção básica, de forma que essa equipe acreditava que 'a atenção básica não tem cumprido a parte de prevenção das ações e o NASF veio na rede preencher essa lacuna' (diário institucional, grifo nosso). Então, nos encontros com o NASF e o CAPS, discutimos a necessidade de convocar a atenção básica e estimular, por meio do matriciamento, o atendimento em saúde mental nesse nível de atenção. Um dos profissionais mencionava que isso era impossível de ser feito, mas outros profissionais da equipe acreditavam na aposta.

De acordo com o Plano Estadual de Saúde de 2012 a 2015, no território do estado pesquisado houve significativo aumento de equipes NASF. Apesar desse aumento, o que se verificou foi que na maioria das vezes o trabalho não vinha sendo inspirado na perspectiva do apoio matricial, havendo enorme necessidade de discussão sobre o papel do NASF na rede (Rio Grande do Norte, 2013).

Dessa maneira, no encontro de avaliação ocorrido no final do primeiro semestre do processo de supervisão,

[...] o psicólogo do NASF apontou que a supervisão tinha se tornado um espaço importante, pois os profissionais precisavam dessa assistência, dessa escuta, de formação, e afirmou que já sentia os efeitos positivos da ação do NASF na saúde mental, pois em um grupo formado junto aos usuários da atenção básica os profissionais já percebiam a diminuição do uso de psicotrópicos pela comunidade. Outra profissional dessa equipe assinalou ainda a importância da supervisão para que o NASF entendesse melhor seu papel em relação à rede de saúde mental e para desconstruir sentimentos de medo que antes ela tinha em relação às pessoas que sofrem de transtornos mentais. Uma ACS [agente comunitária de saúde] também afirmara como ela tinha aprendido a desenvolver algumas intervenções a partir do trabalho conjunto com o NASF (diário institucional). 
Ao voltar à dificuldade de vínculo entre as equipes do CAPS e do NASF, Dorigan (2013), analisando a experiência da Rede Mista de Campinas, em São Paulo, afirma que a partir dos encontros entre as equipes elas podem aumentar seu coeficiente de transversalidade, na medida em que conseguem perceber seus diferentes pertencimentos institucionais. Além disso, o encontro é um caminho importante para a convivência com os dissensos e a produção de novos caminhos. Assim é que por meio das supervisões de rede conseguimos produzir alguns desvios nas rivalidades entre os serviços, gerando em alguns momentos uma assistência compartilhada.

O apoio matricial foi fortalecido na medida em que as discussões na supervisão propiciaram outras articulações do NASF com a atenção básica, fundamentadas na ideia de que "o apoio matricial é um arranjo que depende, fundamentalmente, de espaços coletivos e horizontalizados de discussão e deliberação para se efetivar, bem como do contato entre os profissionais envolvidos" (Dorigan, 2013, p. 571). O 'entre', ou seja, o que se passa no encontro entre profissionais pode vir a modificar uma lógica de funcionamento fragmentado da saúde mental, compondo espaços de apoio e de aprendizado para um atendimento conjunto em saúde mental.

Assim é que o trabalho em saúde mental pode vir a se descentrar dos especialismos instituídos na área, para provocar um diálogo com outros saberes vindos de outros campos de conhecimentos teórico-técnicos e do usuário. Por isso, os espaços de encontros de redes precisam ser compostos por parceiros intersetoriais, que possam auxiliar na produção de um cuidado integral à saúde e, por que não dizer, à vida.

\section{0 cuidado à crise no contexto das redes regionais de cuidado}

Em relação ao cuidado nas redes intermunicipais, muitas interrogações surgiram ao longo do processo de supervisão acerca da continuidade da assistência, principalmente aos usuários que estavam em crise e precisavam de um cuidado intensivo. Tais questionamentos se insinuavam a partir de algumas preocupações: como fazer com que o usuário do CAPS continuasse com sua relação com a família, mesmo no contexto da crise? Como continuar o trabalho de referência da equipe do CAPS I com o usuário do CAPS III? E ainda: o CAPS III estaria preparado para atender o usuário em crise em uma lógica antimanicomial?

Tais preocupações sinalizavam para o desejo de se construir uma linha de cuidado coerente com o modo de atenção psicossocial. Dias e colaboradores (2010, p. 75) destacam que um dos problemas quando uma equipe técnica atende um usuário apenas na crise é que os referenciais terapêuticos criados no PTS do serviço de referência podem se perder, bem como "o contexto da 
crise, o significado das abordagens, fazendo com que os parâmetros de melhora se aproximem da avaliação de sintomas psiquiátricos".

Assim, a atenção à crise por equipes diferentes pode levar à perda de um referencial imprescindível em serviços de atenção comunitária, como a articulação do contexto com o sofrimento psíquico grave (Dias et al., 2010). A equipe do CAPS I esbarrava em muitas dificuldades para que não houvesse a fragmentação do cuidado. Destacamos duas delas: a falta de formação profissional da equipe do CAPS III, pois em decorrência do processo de municipalização a equipe de transição do hospital psiquiátrico para o CAPS III foi modificada, e a nova equipe não tinha formação sobre as propostas na área da Reforma Psiquiátrica (RP); a dificuldade no transporte para a equipe deslocar-se para o município vizinho e assim poder acompanhar o processo de internação vivenciado pelo usuário.

Em um dos encontros, em maio de 2011, uma das assistentes sociais explicou a situação que a equipe havia vivenciado na noite anterior. Um usuário havia recebido alta há dois dias do CAPS III da região e não havia disponibilidade de carro para pegá-lo e levá-lo ao sítio onde morava. No dia anterior, a assistente social e o administrador foram apresentar as atividades desenvolvidas no CAPS em outra cidade. À noite, na viagem de retorno, eles passaram no CAPS III, pegaram o usuário e levaram-no para casa. Porém, durante a viagem, em decorrência de chuvas intensas e do transbordamento de um riacho, houve um problema com o transporte, e eles tiveram que andar um trecho no meio do mato, à noite, sob a luz do celular e sob a guia do usuário. Nesse trajeto, a assistente social teve muito medo, porém o usuário tentava acalmá-la ao longo do caminho. Os técnicos falavam da situação rindo, porém expressando o medo diante disso, e diante do risco de serem atingidos por um raio no meio da noite. Ficamos extremamente impressionados com a atitude dos técnicos diante do que eles viveram nessa situação (diário institucional)

A falta de transporte apareceu como dificuldade grave vivenciada pela equipe para assistir o usuário. Então, percebe-se que a equipe lidava com tais situações com arranjos, 'jeitinhos' para que o usuário pudesse ser minimamente assistido no tempo necessário.

No que se refere à articulação da rede em uma região de saúde, isso se torna um desafio ainda maior. Conforme Jesus (2013, p. 513), a lógica da regionalização compromete "as práticas comunitárias aplicadas no território do usuário e de sua família". Para pensar a regionalização, é urgente que se busque construir estratégias para superar o risco de práticas descontextualizadas e que se pense, minimamente, em espaços de encontros permanentes entre trabalhadores de serviços de diferentes municípios. 
A gestão da rede de cuidado precisa de mais do que uma coesão técnica; precisa que o foco do planejamento passe de "uma lógica prioritariamente municipal para um olhar no que se refere à rede de assistências regionais" (Dias et al., 2010, p. 88). Deve-se considerar como centro das necessidades a população do município e também a da região. Gostaríamos de enfatizar que a supervisão pode vir a ser um dos dispositivos para auxiliar no fortalecimento de um cuidado em rede municipal e intermunicipal. Um dentre tantos outros que precisam ser construídos.

\section{O que essa experiência revela?}

Analisar uma experiência singular de um estado e de uma supervisão-clínico-institucional nos permite perceber as diversas contradições que se apresentam durante a implantação da supervisão nos CAPS e nas redes de atenção à saúde no nível micro. Esse desconhecimento se perpetuou. No caso específico da nossa experiência, percebemos que a encomenda do CAPS apresentou-se de maneira muito conflituosa, tendo em vista a falta de definição de qual seria o CAPS a ser supervisionado. Quando observamos as demandas, vimos que elas contradiziam constantemente as encomendas realizadas, tentando insistir em um tipo de supervisão já instituída, centrada no caso clínico; outras vezes, permeando entre a necessidade de construir PTS, refletir processos de gestão, de fortalecimento de redes de cuidado. Além disso, em relação à supervisão de rede, várias outras demandas precisaram ser analisadas para potencializar seu funcionamento.

A experiência das discussões de casos, para nós, revelou a necessidade de fortalecer, no contexto dos CAPS e da rede de atenção psicossocial, uma proposta em torno de uma discussão que objetive a construção de PTS. Ou seja, a discussão necessária na supervisão deve ser direcionada para a produção de PTS, e o estudo centrado em casos clínicos tão somente corre o risco de reproduzir uma lógica instituída de supervisão de casos, com base em um único saber. Além disso, faz-se necessário direcionar a construção de uma linha de cuidado, na qual um PTS precisa estar articulado à produção de atos assistenciais pelas equipes junto aos usuários, familiares e comunidade (Franco e Franco, 2019). De modo alinhado a essa proposta, no âmbito da formação é mister ultrapassar um modelo de supervisão que estabelece a hierarquização e a fragmentação dos saberes, e assim propiciar o reconhecimento da formação advinda de cada encontro com o usuário.

Quando vemos a supervisão de rede e de CAPS, percebemos problemas relacionados ao modo de estruturação da rede e das relações de sociabilidade entre os diversos profissionais. As relações de disputa reveladas em um pequeno município prejudicaram o fortalecimento de uma rede efetiva de cuidados. Isso indica que, para fortalecer a supervisão de rede, é necessário 
investir em espaços de discussão entre profissionais de serviços diferentes tais como os fóruns (Dorigan, 2013; Dorigan e L'Abbate, 2014) ou mesmo as supervisões de eixo (Oliveira, 2012; Ferigato e Dias, 2013). No caso de pequenos municípios, é urgente a implantação desses dispositivos e seu funcionamento como espaços de encontro entre profissionais da rede de cidades diferentes.

Além disso, acreditamos que tais espaços não devem substituir a supervisão clínico-institucional das equipes dos CAPS. A sua continuidade é fundamental para uma reflexão permanente da equipe sobre as relações clínicas e institucionais aí produzidas, assim como sobre a sua relação com a rede de saúde e intersetorial. Isso torna-se importante principalmente em um contexto de desvalorização de profissionais e investimentos ainda incipientes em formação, tal como tem sido visto no contexto brasileiro.

Os profissionais demandavam falar sobre suas angústias, reapropriar-se de seu cotidiano, analisar suas relações dentro da equipe, com a rede e com a gestão municipal. Essa demanda nos levou a adotar diversos saberes, não centrados no saber do supervisor nem em uma única especialidade, mas englobando os saberes dos diversos sujeitos envolvidos no processo de supervisão. Identificamos um movimento instituinte vivenciado nessas equipes em relação à própria supervisão, que apontou para uma ressignificação da sua função do serviço na rede de atendimento de atenção psicossocial (Severo, L'Abbate e Campos, 2014).

Acreditamos que, por seu caráter de construção permanente, a supervisão precisa proporcionar um aumento do coeficiente de transversalidade no grupo a partir de momentos de experimentação dos trabalhadores como grupos-sujeitos. Isso deve ocorrer principalmente com os supervisores, para que, ao incluírem a análise de suas implicações, possam entender o movimento construído com o grupo, colocando em questão seus saberes, suas implicações profissionais, de modo a constituir assim um dispositivo coerente com os processos desinstitucionalizantes. Só assim acreditamos ser possível construir um modelo de atenção psicossocial no qual possamos reafirmar um convite a vivermos a nossa heterogeneidade (Campos, 2012). 


\section{Colaboradoras}

Ana Kalliny Severo desenvolveu o trabalho de campo, a escrita e as análises apresentadas neste artigo; Solange L'Abbate orientou todas as fases do trabalho e realizou a revisão final do artigo.

\section{Financiamento}

Ana Kalliny Severo recebeu Bolsa concedida pela Coordenação de Aperfeiçoamento de Pessoal de Nível Superior (Capes).

\section{UNA SUPERVISIÓN CLÍNICO-INSTITUCIONAL EN LA REFORMA PSIQUIÁTRICA EN LA PERSPECTIVA DEL ANÁLISIS INSTITUCIONAL}

Resumen La supervisión fomenta cambios en los servicios en la perspectiva de la atención psicosocial. Su institucionalización se realizó en los campos de la clínica, formación y gestión en salud y expresa fuerzas contradictorias instituidas e instituyentes. La investigación que dio origen a este artículo analizó el proceso de supervisión clínico-institucional en dos equipos de la red de salud de un municipio del interior del Nordeste de Brasil. La referencia teórico-metodológica utilizada fue la del análisis institucional, en la perspectiva de la socioclínica. El proceso se realizó en 12 encuentros, de marzo 2011 a febrero 2012, y fue registrado en diarios institucionales. En este proceso, mostramos que: el análisis de la encomienda y, principalmente, la de las demandas movilizaron el proceso de supervisión; existieron conflictos entre el uso de casos clínicos y la construcción de los proyectos terapéuticos singulares, así como también en la comprensión sobre el proceso formativo de la supervisión; hubo cooperaciones y rivalidades entre los equipos en la construcción del cuidado en redes municipales; surgieron desafíos en el cuidado a la crisis en el contexto de las redes regionales en la perspectiva de la atención psicosocial. El dispositivo supervisión debe ser expandido e interiorizado, constantemente revisto, para que este en consonancia con los presupuestos de la atención psicosocial, así como para propiciar momentos de relacionamiento de los trabajadores como grupos-sujetos.

Palabras clave atención psicosocial; análisis institucional; red de atención psicosocial; supervisión en salud mental. 


\section{Referências}

CAMPOS, Gastão W. S. O anti-Taylor: sobre a invenção de um método para co-governar instituições de saúde produzindo liberdade e compromisso. Cadernos de Saúde Pública, Rio de Janeiro, v. 4, n. 14, p. 863-870, 1998.

CAMPOS, Gastão W. S. Paidéia e gestão: indicações metodológicas sobre o apoio. In: CAMPOS, Gastão W. S. (org.). Saúde Paidéia. São Paulo: Hucitec, 2007. p. 85-102.

CAMPOS, Gastão W. S.; AMARAL, Márcia A. A clínica ampliada e compartilhada, a gestão democrática e redes de atenção como referenciais teórico-operacionais para a reforma do hospital. Ciência e Saúde Coletiva, Rio de Janeiro, v. 12, n. 4, p. 849-859, 2007.

CAMPOS, Rosana T. O. et al . Avaliação da rede de centros de atenção psicossocial: entre a saúde coletiva e a saúde mental. Revista de Saúde Pública, São Paulo, v. 43, supl. 1, p. 16-22, ago. 2009.

CAMPOS, Rosana T. O. Psicanálise \& saúde coletiva: interfaces. São Paulo: Hucitec, 2012.

CARVALHO, Juliana F. S.; CHAVES, Lucieli D. P. Supervisão de enfermagem no contexto hospitalar: uma revisão integrativa. Revista Eletrônica de Enfermagem, Goiânia, v. 13, n. 3, p. 546-553, jul./set. 2011. Disponível em: $<$ http://www.fen.ufg.br/revista/v13/n3/pdf/ v13n3a21.pdf>. Acesso em: 7 nov. 2014.

CARVALHO, Laura G. P. et al. A construção de um Projeto Terapêutico Singular com usuário e família: potencialidades e limitações. O Mundo da Saúde, São Paulo, v. 36, n. 3, p. 521-525, 2012.

CASTEL, Robert. A gestão dos riscos: da antipsiquiatria à pós-psicanálise. Rio de Janeiro: Francisco Alves, 1987.

COIMBRA, Cecília. A supervisão institucional como intervenção sócio-analítica. Psicologia, Ciência e Profissão, Brasília, v. 9, n. 1, p. 26-28, 1989.
COUTINHO, André R., MEDEIROS, Edimárci; TRINDADE, Tarso F. Supervisão em grupo: considerações sobre um dispositivo clínicoinstitucional. Mnemosine, Rio de Janeiro, v. 8, n. 2, p. 24-50, 2012.

DIAS, Marcelo K. et al. Formação de redes intermunicipais substitutivas em saúde mental: a experiência do Seridó potiguar. In: LANCETTI, Antonio; CAMPOS, Florianita B. (org.). SaúdeLoucura: experiências da reforma psiquiátrica. v. 9. São Paulo: Hucitec, 2010. p. 73-90.

DORIGAN, Juliana. Fóruns colegiados de Saúde Mental de Campinas: o caso da Rede Mista à luz da análise institucional. In: L'ABBATE, Solange; MOURÃO, Lúcia C.; PEZZATO, Luciane (org.) Análise institucional e saúde coletiva. São Paulo: Hucitec, 2013. p. 560-578.

DORIGAN, Juliana; L'ABBATE, Solange. Rede mista: espaço transversal à construção do conhecimento e produção de práticas de saúde mental. Saúde Debate, Rio de Janeiro , v. 38, n. 100, mar. 2014.

FERIGATO; Sabrina H.; DIAS, Marcelo K. A supervisão clínico-institucional: um dispositivo teórico-prático para o fortalecimento das redes em saúde mental. In: DIAS, Marcelo K. Dispositivos de atenção em saúde mental e seus desafios. Natal: EdUnP, 2013. p. 83-102.

FOUCAULT, Michel. O poder psiquiátrico. São Paulo: Martins Fontes, 2006.

FRANCO, Camila M.; FRANCO, Túlio B. Linhas do cuidado integral: uma proposta de organização da rede de saúde. Disponível em: < http://www.saude.sp.gov.br/resources/humanizacao/homepage/acesso-rapido/formacaotecnica-em-acolhimento-na-atencao-basica/ passo_a_passo_linha_de_cuidado.pdf $>$. Acesso em: 23 maio 2014.

FUKS, Lúcia B. Formação e supervisão. Psicanálise e universidade, São Paulo, n. 16, p. 79-91, 2002. 
HESS, Rémi. Momento do diário e diário dos momentos. In: ABRAHÃO, Maria H. M. B.; SOUZA, Elizeu C. (org.). Tempos, narrativas e ficções: a invenção de si. Porto Alegre: EdiPUCRS, 2006. p. 89-103.

INSTITUTO BRASILEIRO DE GEOGRAFIA E ESTATÍSTICA (IBGE). Censo demográfico de 2010. Disponível em: <https://censo2010.ibge. gov.br/sinopse/index.php?uf=24\&dados $=1>$. Acesso em: 30 abr. 2019.

JESUS, Aidecivaldo F. A institucionalização de um serviço de saúde mental em um município de pequeno porte. In: L'ABBATE, Solange; MOURÃO, Lúcia C.; PEZZATO, Luciane M. (org.). Análise institucional e saúde coletiva. São Paulo: Hucitec, 2013. p. 510-533.

L'ABBATE, Solange. Análise Institucional e Intervenção: breve referência à gênese social e histórica de uma articulação e sua aplicação na Saúde Coletiva. Mnemosine, Rio de Janeiro, v. 8, n. 1, p. 194-219, 2012.

LOURAU, René. A Análise institucional. Petrópolis: Vozes, 1975.

LOURAU, René. Análise Institucional e práticas de pesquisa. Rio de Janeiro: EdUERJ, 1993.

LOURAU, René. Objeto e método na análise institucional. In: ALTOÉ, Sonia (org.). René Lourau. Analista Institucional em tempo integral. São Paulo: Hucitec, 2004a. p. 66-86.

LUZIO, Cristina A. Atenção psicossocial e psiquiatria biológica: uma trajetória histórica. In: L'ABBATE, Solange; MOURÃO, Lúcia; PEZZATO, Luciane (org.) Análise institucional e saúde coletiva. São Paulo: Hucitec, 2013. p. 471-509.

MONCEAU, Gilles. Como as instituições atravessam as práticas profissionais: socioclínica institucional e formação de professores. In: PIMENTA, Selma G.; FRANCO, Maria A. S. (org.). Pesquisa em educação: possibilidades investigativas/formativas da pesquisa-ação. v. 1. São Paulo: Loyola, 2008. p. 27-73.
MONCEAU, Gilles. Techniques socio-cliniques pour l'analyse institutionnelle des pratiques. In: MONCEAU, Gilles (org.). L'analyse institutionnelle des pratiques: une socio-clinique des tourments institutionnels au Brésil et en France. Paris: L'Harmattan, 2012. p. 15-35.

OLIVEIRA, Gustavo N. O projeto terapêutico singular. In: CAMPOS, Gastão W. S.; GUERRERO, André V. P. (orgs.). Manual de práticas da atenção básica: saúde ampliada e compartilhada. São Paulo: Hucitec, 2008. p. 273-282.

OLIVEIRA, Joana. Efeitos transversais da supervisão clínico-institucional na rede de saúde mental. 2012. 124 f. Tese (Doutorado em Psicologia Clínica) - Departamento de Psicologia, Instituto de Ciências Humanas e Filosofia, Universidade Federal Fluminense, Niterói, 2012.

PEZZATO, Luciane M.; L'ABBATE, Solange. O uso dos diários como ferramenta de intervenção da Análise Institucional: potencializando reflexões no cotidiano da Saúde Bucal Coletiva. Physis: Revista de Saúde Coletiva, Rio de Janeiro, v. 21, n. 4, p. 1.297-1.314, 2011.

RODRIGUES, Heliana C.; SOUZA, Vera L. A Análise Institucional e a profissionalização do psicólogo. In: KAMKHAGI, Vida R.; SAIDON, Osvaldo (org.). Análise institucional no Brasil. Rio de Janeiro: Espaço e Tempo, 1987. p. 27-46.

TEDESCO, Silvia; SOUZA, Tadeu. Territórios da clínica: redução de danos e os novos percursos éticos para a clínica das drogas. In: CARVALHO, Sergio; FERIGATO, Sabrina; BARROS, Maria E. (org.). Conexões: saúde coletiva e políticas de subjetividade. Hucitec: São Paulo, 2009. p. 141-156.

ROUDINESCO, Elizabeth. Por que a psicanálise? Rio de Janeiro: Zahar, 2000.

RIO GRANDE DO NORTE. Secretaria Estadual de Saúde Pública (SESEP - RN). Plano Estadual de Saúde 2012-1015. Rio Grande do Norte: SESAP- RN, 2013. 
SARAIVA, Lisiane A.; NUNES, Maria L. T. A supervisão na formação do analista e do psicoterapeuta psicanalítico. Estudos de Psicologia, Natal, v. 12, n. 3, p. 259-268, 2007.

SEVERO; Ana K. S.; L'ABBATE, Solange; CAMPOS, Rosana T. O. A supervisão clínicoinstitucional como dispositivo de mudanças na gestão do trabalho em saúde mental. Interface: Comunicação, Saúde, Educação, Botucatu, v. 18, n. 50 , set. 2014 .
SEVERO; Ana K. S. A institucionalização da supervisão na reforma psiquiátrica brasileira: (re)produção de controles e desvios junto às equipes de Saúde Mental. 2014. 255f. Tese (Doutorado em Saúde Coletiva)- Universidade Estadual de Campinas, Faculdade de Ciências Médicas, Unicamp, 2014.

ZASLAVSKY, Jacó; NUNES, Maria L. T.; EIZIRIK, Cláudio L. A supervisão psicanalítica: revisão e uma proposta de sistematização. Revista de Psiquiatria do Rio Grande do Sul, Porto Alegre, v. 25, n. 2, p. 297-309, 2003. 